\title{
Percursos poéticos da voz
}

\author{
José Batista Dal Farra Martins \\ (Zebba Dal Farra)
}

O significado exato de poética é o estudo de uma obra a ser feita. O verbo "poein", do qual a palavra deriva, significa exatamente fazer ou fabricar. (...) A poética da música - é justamente sobre isso que vou falar a vocês; isto é, falarei sobre o fazer no campo da música (Igor Stravinsky: Poética Musical em 6 Lições).

\section{A voz e suas poéticas}

Noras a gama das especificidades da pesquisa teatral, a voz do ator ocupa um lugar especial e de grande interesse, por sua potência criativa, em conexão com outros elementos, associados ao desempenho do ator e à encenação. A despeito de sua invisibilidade, a voz se concretiza como som, palavra, ruído e silêncio, nos movimentos de pulso e tom, nos contrastes das intensidades, na sinuosidade dos cromatismos, na dança prosódica das inflexões, na diversidade de timbres engendrados pelas ressonâncias: em sua música. O senti$\mathrm{do}^{1} \mathrm{da}$ voz do ator estampa-se nesta música, por meio de vetores internos que a impulsionam e nela imprimem, de forma fugaz, imagens e conceitos, paixões e pensamentos, desejos e reflexôes. É na realidade física da onda sonora que a voz se coloreia, se amplifica e percorre o ar no sentido de seu destino: o outro. A voz emana do corpo e toca, se embrenha, provoca, age sobre o corpo do outro e o transforma. A voz é experiência que se realiza entre os corpos. A este respeito, no percurso de conceituação da performance, o medievalista Paul Zumthor evoca uma lembrança parisiense: "a canção que cantava o ambulante de minha adolescência implicava, por seus ritmos (os da melodia, da linguagem e dos gestos), as pulsações do corpo desse cantor, mas também do meu e de todos nós em volta. Implicava o batimento dessas vias concretas, em um momento dado; e durante alguns minutos esse batimento era comum, porque a canção o dirigia, submetia-o à sua ordem, a seu próprio ritmo. A canção tirava dessa tensão, portanto, uma formidável energia que, sem dúvida nem o pobre diabo do cantor nem eu, seguramente, aos doze anos, tínhamos consciên-

José Batista Dal Farra Martins (Zebba Dal Farra) é músico, encenador e professor do Departamento de Artes Cênicas da ECA-USP.

1 Utilizo a distinção proposta por Matteo Bonfitto, de "caráter puramente pragmático", considerando-se "sentido" "o efeito de um processo de conexão entre as dimensōes interior e exterior do ator, desencadeado a partir de suas ações” (Bonfitto, 2005, p. 26). 
cia: a energia propriamente poética" (Zumthor, 2000 , p. 46). Eis alguns ingredientes para a construção de fazeres no campo da voz para o ator, processos denominados Poéticas da Voz. O enfoque poético da voz supera o caráter utilitário da voz cotidiana, pela valorização de sua música como produtora de sentido. Desta proposta decorre que a voz, seja som, palavra, ruído ou silêncio, canto ou fala, se apresenta como dicção musical, pois que se compõe de pulsos e tons: de ritmo. A trama do tecido dos significantes, enredada pelo ritmo da voz poética do ator, captura o ouvinte e amplia as possibilidades de diálogos com o sentido e o significado da mensagem.

A estrutura pedagógica da voz poética não é linear, mas se constitui em um sistema tridimensional, em que todos os elementos interagem, são interdependentes. Embora seja possível focalizar cada um dos seus potenciais para percebê-lo, estudá-lo e aperfeiçoá-lo, por meio de teorias e técnicas específicas, há um princípio de interferência que se induz do campo interdisciplinar da voz para o campo teatral. No campo da voz, fatores físicos e psicofísicos devem ser considerados agentes de som e sentido que atuam em sinergia, situação em que a ação coletiva coordenada é potencializada pelas açōes dos fatores. O princípio sinergético irriga também o campo teatral, onde a cooperação de diversas linguagens engendra a encenação. Não se trata, portanto, de adição linear de partes independentes, mas de integração orgânica de partes interdependentes. Como a voz é um dos componentes da encenação teatral e seu desempenho é fortemente sensível aos fatores envolvidos no processo criativo, o treinamento vocal não deve perder de vista sua perspectiva poética. As poéticas da voz determinam e definem técnicas associadas, como conjuntos de práticas de aprendizagem, destinadas a superar desafios específicos que se colocam. Um construtor de casas deve saber edifica-las, mas certamente atentará para as especificidades relativas, por exemplo, aos materiais utilizados. Se de madeira, deverá dominar a arte dos encaixes e da fixação por pregos e parafusos. Se de concreto, a dosagem de cimento, pedra e areia, o projeto de armação e a confecção das formas. Do poeta construtor espera-se, por exemplo, a definição do desenho e caimento dos telhados e a disposição interna dos ambientes. A voz é vibração do corpo, posta em movimento pelo desejo. O corpo do ator, como instrumento produtor da voz, centraliza os atributos técnicos e poéticos, tratando-se seu trabalho de buscar o ponto de equilíbrio da mistura, pois o foco excessivamente técnico em potenciais específicos da voz conduz freqüentemente à preocupação com a própria voz. Grotowski aborda este aspecto, quando afirma que "o ator preocupado com a própria voz concentra toda a atenção no instrumento vocal: enquanto trabalha, observa-se, escuta-se, freqüentemente duvida de si mesmo, mas também se não experimenta dúvidas, comete um ato de violência contra si. Com o simples ato de observar, interfere constantemente no funcionamento do instrumento vocal" (Grotowski, 2007, p.142). Num acordo com o ar, alça-se a voz como pipa e depois se deixa que voe, empinando-se volta e meia, para impulsioná-la em sua navegação. A voz poética - som, ruído, silêncio e palavra - atrela-se organicamente ao corpo do ator, seu instrumento, colocando-se no espaço-tempo cênico como um dos elementos da encenação. O entendimento da voz como um sistema imerso sinergeticamente no sistema teatral implica em que o seu enfoque poético será indutivo, sem que se perca, passo a passo, o confronto das partes com o todo.

Deseja-se, portanto, a coesão orgânica entre técnica e poética, para o que se revela importante a enunciação de alguns requisitos, princípios que definirão um território pedagógico das poéticas da voz do ator.

\section{Afinação}

O primeiro ato de um processo de treinamento poético da voz é de importância cardinal, pois dele depende a instauração de uma atmosfera 
teatral, sagrada em sua essência, em oposição aos ritmos profanos da dimensão cotidiana: é movimento de fundação de um mundo (Eliade, s/d, p. 36). Esta ação inicial determina a qualidade do processo e depende do fomento a uma específica concentração, atrelada às relações entre os indivíduos participantes, atentando-se para a temperatura do processo, mais importante que o próprio processo, segundo Barba (Feral, 2003, p. 54). Contém, portanto, os atributos de aquecimento e preparação, terminologia difundida no vocabulário teatral, mas que não traduz plenamente os requisitos do ato. Além de aquecer e preparar, se trata de afinar o instrumento corporal da voz do ator, ação individual que se faz coletiva na afinação com o outro, percurso que se cumpre a cada encontro. A afinação da orquestra, em que cada instrumento imprime sua assinatura sonora, a partir do dó de referência dado pelo oboé, abre uma espécie de fenda no tempo, instante que pressente o apagar das luzes e o início do concerto, cuja evolução pressupõe a sustentação da afinação. Afinar é acordar, entrar em acordo consigo e com o outro, ação exploratória que exige do ator as habilidades do navegador que atraca o seu barco e aborda o território, tateia o espaço com todas as suas antenas em plena atividade, pois que à sua frente apresenta-se o desconhecido. Afinar é também refinar, apurar, lapidar, ações extremamente desejáveis como estímulos ao trabalho do ator no teatro, frequentemente apoiado na repetição. A afinação pode ser pensada como convergência de dois estados complementares: estado de escuta e estado de música. ${ }^{2}$
A escuta cultiva a qualidade da observação, convocando-se os sentidos - visão, audição, olfato, paladar e tato, no sentido de si, do outro e do espaço. Por um lado, coloca-se como condição necessária para o desenvolvimento de práticas corporais e vocais, que promovam o equilíbrio tônico e impulsionem sua expansão. Por outro lado, expõe o ator no espaço, em suas dimensões do eu, no contato com seu íntimo reduto, da pessoa, na relação com o outro, e do cidadão, nas conexões com o espaço: vetores que migram do campo privado ao campo público. $^{3}$ A voz do outro me toca assim como a minha voz toca o outro. A compreensão desta troca de toques se faz com o cultivo e a construção de uma escuta, fruto de desejo e de escolha.

O estado de música busca a integração das pulsaçôes corporais e vocais, pelos ritmos das palavras e dos cantos, harmonizando-se os movimentos da voz e do corpo. A musa Melpômene, aquela que cantadança, é sua remota inspiração. Palavras-cantadas, evocadas pelo rapsodo, as nove musas, nascidas da união de Zeus com a deusa Mnemosine, "antes que o alfabeto entorpecesse a Memória” (Torrano, 1992), num tempo em que não havia a língua escrita, conservam os atributos ancestrais do poder e da memória. A voz porta as marcas da história do sujeito, frutos de sua memória pessoal e cultural, impregnadas de desejo, poder que o impulsiona para o desconhecido. Por meio do ritmo, o estado de música catalisa estas polaridades, para acionar a centelha da presença plena do corpo da voz do ator. Música cantada, coletiva, ponto de explosão do rito teatro, o estado de

2 José Celso Martinez Correa, ator e diretor do Teatro Oficina, cunhou a expressão "estado de música" em oposição ao "estado de prosa", centrado na voz cotidiana e utilitária.

3 A nomenclatura baseia-se na abordagem de Marilena Chauí para a consciência, em que o eu, a pessoa e o cidadão, associados, respectivamente, às dimensões psicológica, ética e política, são articulados pelo sujeito do conhecimento, sua dimensão epistemológica (Chauí, 2003, p. 130-1). A prática de afinação correspondente, difundida pelo bailarino, coreógrafo e professor Klauss Vianna, e me apresentada por um de seus assistentes, José Maria de Carvalho, nos trabalhos que desenvolvemos, entre 1987 e 1990, traz marcas dos círculos de atenção (Stanislavski, 2002, p. 104-28). 
música configura-se como estado poético de criação teatral, em que "não sou eu que canto a canção, é a canção que me canta", motivação formulada pelo encenador romeno Andreï Serban (Banu, 1995, p.55), que encontra eco na canção "Timoneiro", de Paulinho da Viola e Hermínio Bello de Carvalho: "não sou eu quem me navega, quem me navega é o mar, é ele quem me carrega, como nem fosse levar." A música passeia pela pele, chega ao coração, à cabeça e toma todo o corpo (Martins, 2005, p. 53).

Experiências coletivas, vetores de interferência, de interação, de provocação, apontados para o outro, estado de escuta e estado de música correspondem ao receptivo e ao criativo, polaridades que se alternam e se completam, freqüentemente em luta, no processo poético da voz. Enquanto o estado de escuta seleciona e focaliza, o estado de música integra e funde. A afinação, sua síntese, projeta o ator no espaço e no coletivo de trabalho, assemelhando-se à organicidade arquitetônica, quando se pressupõe que a edificação se enraize no solo como mãos que penetram na terra. Se os pés do ator são suas raízes, seu corpo e sua voz em movimento são o instrumento de abordagem e conquista: vetores que se lançam no sentido do outro. A afinação é, simultaneamente, atividade exploratória e preparatória do corpo e da voz: ponto de superação entre o receptivo e o criativo.

\section{Silêncio, pulso, tom: claros-escuros da voz}

É sempre bom lembrar que um copo vazio está cheio de ar (Gilberto Gil, Copo Vazio).
É do silêncio que emerge o som. O ar que entra silenciosamente pela inspiração é potência da voz: o vazio está cheio de ar, o ar está cheio de voz. Todo silêncio é promessa de voz, que se cumpre quando, no fluxo expiratório, a ação das pregas vocais imprime um sinal de movimento no ar. A onda sonora, colorida e amplificada nas caixas de ressonância, não é matéria, mas vibra e se desloca através da matéria, produzida como som e sentido pelo instrumento corporal do ator.

Há som no silêncio. Da condição de existência de uma escuta humana viva decorre que, mesmo com todo o ruído de fundo anulado, por meio de um isolamento absoluto do exterior, restará ao ouvinte o som de seu pulso grave e ritmado, da pulsação de seu sangue, do rumor de seus órgãos em movimento, sobre o pano de fundo branco do sistema nervoso. Conclui-se que as poéticas da voz contêm poéticas do silêncio. O silêncio é a matriz que possibilita o deixar-se tocar, invadir, penetrar pela voz do outro. O silêncio é um ruído do fundo das vozes e das palavras, dos gestos em ação. ${ }^{4}$ O silêncio se coloca como pausa de reverberação e escuta, e, ao mesmo tempo, impulso que movimenta o corpo e a voz. ${ }^{5}$

Inversamente, há silêncio no som. Quando alguém diz ou canta palavra ou som, há silêncio tramado nos seus interstícios. A voz como palavra nasce da fricção entre silêncio, som e ruído. As consoantes são pontos de descontinuidade no contínuo sonoro das vogais. A analogia com o esquema estrutural do esqueleto humano sugere a associação das vogais a ossos e das consoantes a articulações, condicionando-se o movimento corporal à atuação coordenada entre estes dois elementos: ossos

4 Ação corporal e vocal significam movimentos dotados de sentido, cujos vetores apontam para o outro. É na relação com o outro que se estabelece a conversa de pulsos, pausas e tons, que engendra os ritmos das açôes.

5 Uma fisiologia do silêncio ensina que quem o provoca é a ação muscular sobre duas cartilagens, impondo-se o afastamento das pregas vocais e a respiração silenciosa. 
desarticulados empilham-se ou se enrijecem. Nesta perspectiva, o movimento da voz poética depende da precisa articulação das vogais pelas consoantes, buscando-se o equilíbrio entre clareza e fluxo vocal, para os quais contribuem vetores internos, ligados ao conceito e à imagem da palavra. Se a voz como palavra é luz, o silêncio é sua sombra. $\mathrm{Na}$ voz há silêncio, como sombras, que percorrem seus subterrâneos, fertilizam a luz das palavras, impulsionam o movimento das imagens. Como em uma pintura, o colorido da voz é função não só do cromatismo e das nuances da entonação, mas dos contrastes entre claro e escuro, som e silêncio, criativo e receptivo. A sombra da palavra subjaz na voz poética ininterruptamente, na alternância cíclica entre impulso, ação e sustentação, vetores com componentes internos e externos. A comprovação de que há silêncio no som é acústica. Tome-se, por exemplo, o pulso do coração como referência a um andamento de marcha: cada batida, um passo. É evidente o silêncio que se faz entre cada pulso, e que estamos no domínio do ritmo corporal. Se subdividirmos a pulsação de forma crescente, marcando com as palmas das mãos, há um estreitamento crescente das duraçôes das pausas, pela multiplicação dos pulsos. Existe uma região-limite, situada entre 13 a 20 pulsos por segundo, abaixo da qual se conserva a percepção do conjunto de pulsos como andamento. Aumentando-se progressivamente a pulsação, para além deste patamar, os pontos silenciosos fundem-se na percepção do ritmo como som, isto é, como alturas, como tom. Os sons graves guardam esta relação mais íntima com a gravidade, já que se encontram próximos da zona de passagem e, portanto, do fenômeno rítmico como jogo explícito entre o som e o silêncio. Conseqüentemente, a continuidade do som é aparente, pois que ele sempre contém pulsos de silêncio em seu interior. ${ }^{6}$ Percebemos o som como pulso até a região-limite, zona de definição dúbia, a partir da qual o distinguimos como tom. Esta visão física integradora, que compreende pulso, silêncio e tom como faces de um mesmo fenômeno, sugere um fértil caminho para a construção do jogo entre imobilidade, movimento, pausa e voz, cujo eixo baseia-se no ritmo. Combinando-se a estes quatro fatores, seja como som, ruído ou palavra, encontram-se quatro possibilidades, associados à coincidência entre pausa e imobilidade, pausa e movimento, voz e imobilidade, voz e movimento. Há ainda o conjunto dos muitos arranjos em que não há coincidência entre pares de fatores, mas divergência entre eles. No campo da voz poética, as associações com as fases do ciclo respiratório incrementam os diálogos com o gesto: a inspiração é o impulso da ação expiratória, fluxo que se sustenta e se renova na pausa de retomada do ciclo. Projeta-se, assim, uma estrutura cênica básica, malha que permitirá a ação coordenada entre corpo e voz, incluindo-se, no percurso, outros recursos da voz. Atributos do silêncio na voz e no movimento, pausa e imobilidade colocamse em suspensão, como nos pontos de energia potencial máxima de um pêndulo, estimulando-se o fluxo contínuo do corpo da voz do ator, pelo impulsionar constante e recíproco. ${ }^{7}$ O copo do silêncio está cheio de ar, potência de voz como desejo, conceito, imagem e música.

6 Para uma descrição complementar, e enriquecida pelo CD de Hélio Ziskind, que acompanha o livro, consultar a abordagem de Wisnik, 1989, p. 15-28.

7 Analogia proposta por Patrícia Noronha, em suas aulas de Corpo e Movimento, no Departamento de Artes Cênicas. 


\section{Sujeitos da voz}

Ser significa comunicar-se pelo diálogo (Bahktin).

O corpo é o instrumento da voz, cuja matéria é o ar: a inspiração é impulso do ar que se faz voz na ação expiratória. Voz é um sinal impresso no ar. $\mathrm{O}$ ar, como objeto de percepção e domínio, é elemento central no enfoque de Myrian Muniz, pedagoga em tempo integral, mestra de um teatro peripatético, voador, como ela dizia. Durante vinte anos, de 1984 até sua morte, em 2004, convivi estreitamente com ela, como aprendiz de teatro, em uma relação que transbordava os limites do trabalho teatral convencional, espalhando-se criativamente em nossas vidas. Corpo, voz e palavra são elementos fundadores em seu teatro, concebidos como unidade indissociável e alçados ao desempenho pela improvisação, um jogo com o acaso, sempre na perspectiva da relação com o outro, lapidada cotidianamente, no processo da criação teatral. Para Myrian, o campo de jogo tem que ser preparado e cultivado pelos atores, como semeadores que prenunciam a sova sagrada do pão. Os altares multiplicavam-se na sua casa, em cada canto um mistério, a foto do filho atrás do pneu, as gamelas, a mesa e o banco de madeira, os quadros de Flávio Império, a Dorina que parecia um sofá, livros, luzes de uma ribalta caseira, a multiplicação dos pequenos ambientes: tudo em volta dela era espaço de conhecimento teatral. Na primeira vez em que dirigi um trabalho de voz com um grupo de seus alunos, ela se sentou face a face comigo e disse, bem devagar, com sua voz grave e pausada: você vai olhar para o ser, e logo você vai perceber do que ele precisa.

Uma das propostas pedagógicas de Myrian Muniz é o princípio que incita o culti- vo do olhar atento, escuta que se expõe na relação viva com o ser, acessada pela intuição e pelo improviso. O ser é continente e superação do ator, em diálogo com o sujeito, o eu, a pessoa, o cidadão, sua memória e sua história: o campo pedagógico do teatro e, em particular, da voz poética, tem lugar neste espaço interpolar de interseção e passagem, campo de experiência e, portanto, sujeito a desafios e riscos. A voz do ator torna-se poética em relação sinérgica com a voz do indivíduo, com seus medos e desejos, sem que se neguem, portanto, as tensões desta relação. Um corolário deste lema é que a expansão das possibilidades vocais do ator amplia, como conseqüência, as possibilidades do ser, ao mesmo tempo em que toda descoberta e todo movimento cênico implica em transformação também de quem vê, ouve, recebe e compartilha do evento teatral.

Neste espaço de travessia do ser, a voz poética do ator reverbera sons, silêncios e palavras, em percursos cujos pólos são o íntimo e o público, que podem ser associados às manifestaçôes lírica e épica. Se o sujeito do épico é o narrador, o sujeito do lírico será o cantor. Para o cantor que não narra, a sonoridade é plena, completa e soberana. A voz deste cantor soa como "alguém cantando longe daqui", mas "vem do coração": tão perto e tão profunda, por isso distante. O que não se pode mais dizer, é preciso cantá-lo, afirma Heiner Muller. ${ }^{8}$ É "a voz de alguém nessa imensidão, (...) a voz de um certo alguém, que canta como que pra ninguém." 9 A voz deste cantor é pulsação intransitiva e se faz renovadamente presente pelo ato de cantar. Ao narrador que não canta corresponde a voz completamente utilitária. Pela dosagem de cantor e narrador, obtêm-se muitas combinações ou fundem-se muitas ligas: narradores que cantam, cantores que narram, rapsodos e cantadores, artistas performáticos no território do ator.

8 Ce dont on ne peut plus parler, il faut le chanter. Citado por Banu, 1995, p. 7.

9 Caetano Veloso: Alguém cantando. 
Exemplo de sujeito cantor que narra, o samba de breque ${ }^{10}$ gera interessantes possibilidades poéticas da voz, especialmente se em conexão com o enfoque brechtiano de alternância entre envolvimento e distanciamento da ação narrativa. No desenvolvimento deste seu projeto, Brecht propõe ao ator que cante contra a canção, formulação que sugere a relação entre o narrador e o cantor como luta, travada pelo ator, no campo de tensão entre estes dois sujeitos. O samba de breque - em que há pelo menos dois sujeitos: um se coloca dentro da cena, enquanto o outro comenta o enredo, passo a passo - exemplifica uma estrutura atraente para o fomento de uma pedagogia da voz poética forjada no universo brechtiano.

\section{A Canção Popular Brasileira como campo poético da voz}

A concepção do trabalho poético da voz como experiência protagonizada pelo ser implica, por um lado, no apuramento da auto-percepção e no re-conhecimento da própria voz - um conhecer que se nutre e se transforma continuamente. Por outro lado, implica em enfrentar as limitaçóes impostas pela voz utilitária, correspondente à fala cotidiana, que Bakhtin classifica como gênero discursivo primário. Os secundários "aparecem em circunstâncias de uma comunicação cultural mais complexa e relativamente evoluída, principalmente escrita: artística, científica, sociopolítica.” Aos gêneros secundários pertencem, portanto, os percursos poéticos da voz, que, "durante o processo de sua formação, (...) absorvem e transmutam os gê- neros primários. (...) Os gêneros primários, ao se tornarem componentes dos gêneros secundários, transformam-se dentro destes e adquirem uma característica particular: perdem sua relação imediata com a realidade existente e com a realidade dos enunciados alheios." 11 Assim, mesmo nas pesquisas teatrais inspiradas no cotidiano, a voz será sempre poética, pelo processo de redimensionamento de seus componentes primários, nos níveis do som e do sentido.

Historicamente, inúmeras tradições teatrais propiciaram a formulação de poéticas da voz para o ator, freqüentemente associadas a escolas e grupos, constituídos em torno de autores e sua época. A dicção shakespeareana, construída do ritmo dos pentâmetros iâmbicos transposição poética do dizer cotidiano, e a musicalidade dos alexandrinos racinianos, moldada na difícil acústica do Hôtel de Bourgogne, são exemplos contundentes de poéticas da voz que se propagaram pela tradição. Desvinculadas dos seus contextos originais, tornam-se técnicas, muitas vezes redundantes na busca de preencher os requisitos pedagógicos da voz poética.

No Brasil, as tradições mais potentes, do ponto de vista da vocalidade poética, vinculamse à cultura popular, nas imbricações da dança, da música e do teatro. Neste universo, a Canção Popular Brasileira apresenta o maior poder de difusão, pois que as canções circulam obstinadamente em nossa memória coletiva: no Brasil, tudo tem vozes cantando um fundo musical. Hábeis compositores passeiam por uma diversidade de temas, iluminam cenas do dia-adia, estampam a alma feminina e masculina, passam em revista fatos da vida brasileira, estimulam comportamentos e críticas, insinuan-

10 Tipo de samba com breques repentinos, nos quais o cantor, dizendo ou cantando, comenta a ação. Exemplos de mestres do gênero são Moreira da Silva, Jorge Veiga, Wilson Batista, Geraldo Pereira e Miguel Gustavo. Em São Paulo, há um tipo de samba semelhante, difundido pelo cantor Germano Mathias, chamado sincopado, em que o comentário, em geral cantado, prescinde do breque.

11 In BAHKTIN, M. Estética da Criação Verbal. São Paulo: Martins Fontes, 1997. Citado por Märtz, 2002, p. 91. 
do-se os corpos pelos pulsos e tons, pelos ritmos e melodias. A canção brasileira, plena de beleza das vozes que sintetizam e amaciam a fala cotidiana, constitui um fascinante portal de acesso ao campo poético da voz, na lavra de terra fértil para a prospecção e a descoberta.

\section{0 Dossiê Voz}

Para o campo de pesquisa da voz convergem fontes de conhecimentos de diversas áreas, tais como Teatro, Música, Dança, Fonoaudiologia e Lingüística, que se interpenetram e cujo foco central se elege de acordo com os requisitos e as propostas da investigação. No âmbito da pedagogia da voz poética do ator, em que o eixo gravitacional é o teatro, distinguem-se dois tipos de relação. Ao primeiro pertencem atores, encenadores e outros profissionais da cena, que se deparam com as complexas questóes da voz no teatro e, por paixão, necessidade ou oportunidade, impelem-se para um aprofundamento nesta área. Compõem o segundo tipo cantores, fonoaudiólogos e outros profissionais da voz, que, por paixão, necessidade ou oportunidade, elegem o teatro como espaço de pesquisa e aplicação de seus conhecimentos. Embora o teatro se situe na confluência destes profissionais, o percurso de cada um impacta profundamente no lugar de onde se fala e, portanto, no processo pedagógico associado. A pluralidade de origens e de caminhos para a formação do professor de voz mostra não só a extensão das questões envolvidas, como amplifica a qualidade dos enfoques. O Dossiê Voz que se apresenta nessa Sala Preta visa a captar esta diversidade de abordagens das questôes da voz e da pedagogia da voz para o ator, partindo-se das contribuições de representantes de cinco instituiçôes paulistas de ensino e pesquisa: Universidade de Campinas (Unicamp), Escola de Arte Dramática (EAD), Pontifícia Universidade Católica de São Paulo (PUC-SP), Universidade Estadual Paulista (Unesp) e Universidade de São Paulo (USP).

Sara Lopes revela a potência da Canção Popular Brasileira como modo de abordagem e estímulo para uma vocalidade poética que leve o ator a "manipular a plasticidade de seu material vocal na riqueza sonora de seu idioma." Isabel Setti parte de um diálogo com uma tradição pedagógica da voz para o ator, representada pela professora Mylene Pacheco, para uma viagem investigativa em busca de uma voz "fruto da totalidade do ser em escuta. Do estado pleno de atenção. Dos nervos expostos, disponíveis para reagir aos estímulos em tempo presente." Luiz Augusto de Paula Souza (Tuto), apoiando-se nos conceitos molar e molecular, de Gilles Deleuze e Felix Guattari, constrói duas possibilidades de abordagem para o trinômio voz, corpo e linguagem. Suely Máster aprimora os procedimentos da análise vocal, no sentido de uma avaliação objetiva da qualidade vocal, destinada a embasar o treinamento vocal do ator: propõe que se coloque ciência no feitiço. Fechando o conjunto de seis artigos que compõem o Dossiê Voz, Fábio Cintra aborda a formação do ator, sob a ótica da voz e da musicalidade, em que preconiza o canto coral como estratégia para a musicalização no teatro.

Desejamos que o Dossiê Voz contribua para o debate sobre a Voz no Teatro, estimule os diálogos entre os pesquisadores da área, colabore para a definição e a clareza dos diversos territórios possíveis e sirva como referência aos processos pedagógicos associados. 


\section{Referências bibliográficas}

BANU, Georges. De la parole aux chants. Paris: Actes-Sud Papiers, 1995.

BONFITTO, Matteo. Sentido, intensão, incorporação: primeiros reflexôes sobre diferentes práticas inter-culturais no trabalho do ator. São Paulo: Sala Preta, n. 5, 2005.

CHAUÍ, Marilena. Convite à Filosofia. São Paulo: Editora Ática, 2003.

ELIADE, Mircea. O Sagrado e o Profano. Lisboa: Edição Livros do Brasil, s/d.

FÉRAL, Josette. Você disse “training”? Blumenau: O Teatro Transcende, n. 11, 2003.

GAZOLLA, Rachel. Tragédia grega: a cidade se faz teatro. In: CARVALHO, Sérgio de: O teatro e a cidade - liçôes de história do teatro. São Paulo: Secretaria Municipal de Cultura de São Paulo, 2004.

GROTOWSKI, Jerzy. O Teatro Laboratório de Jerzy Grotowski 1959-1969. São Paulo: Perspectiva: SESC; Pontedera, IT: Fondazione Pontedera Teatro, 2007.

MARTINS, José Batista Dal Farra: Caminhos e descaminhos nas Artes. Anais da 4a Mostra de Estudos e Pesquisas sobre a Voz. São Paulo, PUC, 2005.

MÄRTZ, Maria Laura Wey. Preparação Vocal do Ator. In: FERREIRA, Leslie Piccolotto e SILVA, Marta Assumpção de Andrada. Saúde Vocal. São Paulo: Editora Roca, 2002.

STANISLAVSKI, Constantin. A preparação do ator. Rio de Janeiro: Civilização Brasileira, 2002.

TORRANO, Jaa. Ensaio introdutório. In: HESÍODO: Teogonia. A Origem dos Deuses. São Paulo: Iluminuras, 1992.

WISNIK, José Miguel. O Som e o Sentido. São Paulo: Companhia das Letras, 1989.

ZUMTHOR, Paul. Performance, Recepção, Leitura. São Paulo: Editora da PUC-SP, 2000. 